\title{
HUMANITY OR ROBOTICS IN SPACE?
}

\author{
MINORU ODA \\ RIKEN, Hirosawa, Wako, Saitawa, Japan
}

The diagram (Fig. 1) qualitatively exhibits how several important observations will have to be undertaken. Here, I would like to, at least, raise the question or discuss the problem referring to "Man in Space".

My question is as follows: How the man in space, like the Space Shuttle, and the robotics, like Voyager, precede the man in space "and/or" the robotics in the 21st century? I think, the answer is not obvious and we have to be cautious to make decisions. Once we make the decision, we may not be able to go backwards because the investments will be enormous and the impact to all humans will be very deep.

When we say "Man in Space" (e.g. specifically Man on the Lunar Base) we have to distinguish two cases: one is to use humanity as Scientists or Astronomers to work there or as Engineers to construct, refurbish, repair or assemble facilities. Therefore, we have three choices in the 21st century. They are:

1) Full activities of humanity in space;

2) Engineers in space; and

3) Fully robotics.

I don't want to commit to any directions at the moment, but I think that we must be aware of the existence of choices, and be very cautious as we strive to determine the final goal.

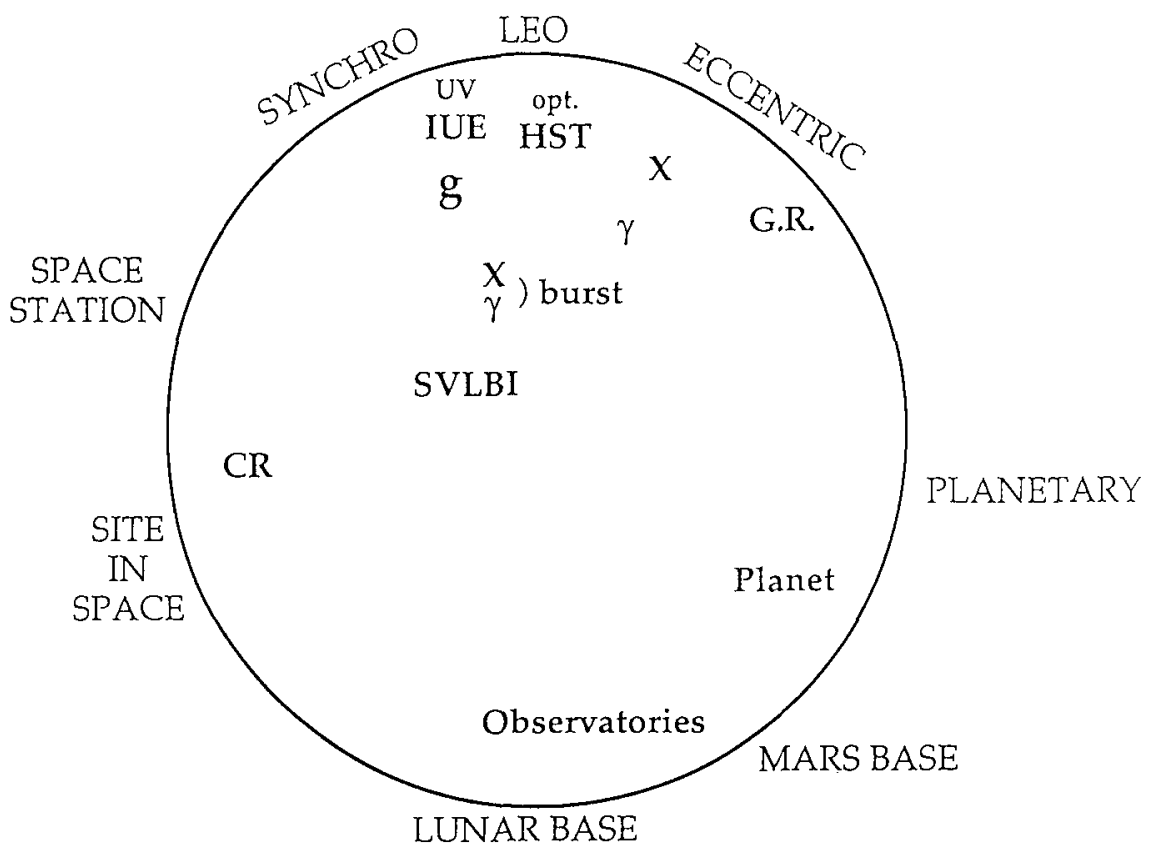

\section{MAN IN SPACE?}

Y. Kondo (ed.), Observatories in Earth Orbit and Beyond, 380.

(C)1990 Kluwer Academic Publishers. Printed in The Netherlands. 